Revista Iberoamericana, Vol. LXXVIII, Núm. 241, Octubre-Diciembre 2012, 1013-1026

\title{
JUZGAR UN JUICIO O LAS ROTURAS DE LO QUE SE COSE CON AFÁN (PUÑO Y LETRA, DE DIAMELA ELTIT)
}

\author{
POR \\ Áurea María Sotomayor-Miletti \\ University of Pittsburgh
}

Las muertes de esta historia vienen a mí

no para que haga oficio de contar desgracias ajenas. José Watanabe, Antígona (43)

I.

Habría que comenzar evaluando el gesto de publicar un texto como éste. Se trata de una llamada "novela” según la Editorial Seix Barral, y está constituída principalmente por documentos judiciales. Habría que considerar, además, las condiciones de lectura que la autora promueve, pues no es éste un texto que dependa de una trama a desarrollar ni de personajes convencionales. Para colmo, el lenguaje característico de los textos jurídicos no estimula el descubrimiento de una acción, de unos personajes ni de un estilo, en sentido literario. La redacción de un caso judicial usualmente consta de una exposición de hechos lo más objetiva posible, el planteamiento de una controversia legal y la aplicación de una norma jurídica a las circunstancias particulares. En el caso penal, el propósito es comprobar que las circunstancias adjudiquen la culpa de acuerdo a la tipificación del delito. Lo que distingue a Puño y letra. Juicio oral (2005) es que se ocupa de ex-poner un jucio, al incluir en el texto las exposiciones y argumentos de los abogados y el interrogatorio formulado a un testigo de corroboración. A ello le suma una breve e intensa evaluación en primera persona de dicho suceso, ocurrido en la Argentina durante la dictadura pinochetista. El gesto no es extraño en la trayectoria de Eltit, pues es evidente el afán documental que ocupa su ademán en El padre mío y El infarto del alma, aunque en esos casos los textos estén investidos de una marginalidad implícita a los personajes centrales de la reflexión: un demente obsedido por una traición deambulando por las calles de la dictadura pinochetista y los infartados mentales de Putaendo, ensimismados en la introspección. En Puño y letra, sin embargo, asistimos a la exposición de unos documentos públicos puestos aquí en circulación general, descolocados del escenario jurídico donde usualmente adquieren su significado como parte del descubrimiento de 
prueba, para comprobar la fidelidad con que se recuerda o la credibilidad del testigo. La conversión, mediante mera trasposición, de un documento público jurídico en un texto novelístico reduplica su significado, pues usualmente dichos documentos públicos, pese al nombre, se confinan al consumo exclusivo y especializado de los juristas. En este texto, un documento público como el testimonio judicial o la exposición oral de los abogados, adquiere otra aura al descontextualizarse y ubicarse dentro de una "novela”, y su significado se altera al convertir el espacio real en un dispositivo estético. Como diría Jacques Rancière, el arte es el dispositivo que lo torna visible mediante el encuadre de un espacio de presentación que reconfigura material y simbólicamente el territorio de lo común (22), el arte es una cuestión de percepción. Mi propuesta es analizar el gesto de Eltit en esta novela al extraer otro significado del acontecimiento jurídico tornándolo visible e insertando en un nuevo espacio la consecuencia de dicho evento. El encuadre, la selección de textos y la valoración que se hace de éste dentro del espacio "fictivo" complica el impacto político del juicio y trasciende las coordenadas convencionales de lo jurídico y de lo estético simultáneamente. La fusión de ambos planos potencia lo que el hecho literario pueda hacer en lo que a justicia se refiere.

Los actos explícitos de valoración por parte de la autora son estratégicos. Surgen en el encuadre previo ("Presentación”) y posterior (“Transversal-mente”) a la inserción de los documentos. De la primera parte destaco que la autora es, por así decirlo, la testigo principal al asistir sistemáticamente al juicio e informarnos todo lo que allí pasa. Tiene razones para estar allí porque se siente "habitante de la dictadura”, aunque descree del proceso o escenario jurídico y manifiesta sentirse distanciada de su propia representación. Después de esta confidencia que repara en la naturaleza traumática y ambigua del texto que nos entrega, la autora enumera algunos puntos, posiciones sustentadas por diversos sectores respecto a este juicio. De éste se ha criticado el enfoque exclusivo en figuras protagónicas del imaginario social y no en los miles de invisibles asesinados, soslayando así el impacto de una mortandad que toca a todos. ${ }^{1}$ Por esta razón, Eltit se autoinculpa al ejercer una "práctica segregadora" que selecciona un crimen notorio para, de la misma forma en que lo ha hecho el Estado, purgar de alguna manera e invisibilizar de otra el asesinato generalizado. También se criticó la explotación de una trama estridente que atrajo la atención hacia un testigo de corroboración, Zambelli, porque el ex-compañero de Arancibia era un bailarín homosexual. Además de recalcar el fragmentarismo de la obra, Eltit misma señala que se trata de un trabajo “estrictamente documental”, aunque añada que es imposible representar cabalmente el "mapa político depredador” (16). En una entrevista concedida a El Mercurio dice: "Pero yo no 'cuento una historia', lo que hago es poner en escena un fragmento documental de orden político que ya formaba

1 La autora lamenta el juicio de estos "ausentes de subjetivación, de relatos que los restituyan vivos, paradójicos, deseantes, biográficos” (15).

Revista Iberoamericana, Vol. LXXVIII, Núm. 241, Octubre-Diciembre 2012, 1013-1026
ISSN 0034-9631 (Impreso) 
parte de la memoria chilena” (Matus). La propuesta pues consiste en exhibir uno de los mecanismos a los que recurrió el Estado para suturar una herida política, consistente en lo que se ha llamado la judicialización. Forma parte del objetivo textual verter directamente los documentos seleccionados por la autora, pero más aún, proveerle un marco, contextualizar el sentimiento general, comentar dichos documentos para iluminarlos de otro modo. El texto o la transcripción del juicio (los dos fragmentos íntegros) hablan por sí solos, y hay en esos documentos jurídicos un sentido de "progreso" que sólo lo capta un jurista. Me refiero al largo interrogatorio a Zambelli que tiene como propósito examinar su capacidad de recordar antes de vincularlo a su relación con Arancibia. En cuanto a las exposiciones de los abogados, éstos se dedican a establecer causalmente la cadena inculpatoria trazando la responsabilidad del Estado y de Pinochet respecto a la agencia de inteligencia, la DINA. Ese captar el "progreso" específico del texto no es crucial para la lectura más ingenua del escrito, por lo que me pregunto si el lenguaje técnico, así como la acumulación de detalles sólo pertinentes en un sentido jurídico podría promover un cierto sentido de "indignación” o "impaciencia" en la lectura convencional que orienta las expectativas de un lector lego. Si el grueso de la novela es esa larga cita extraída directamente del expediente judicial, ¿entonces, qué función desempeña reiterar mediante la extensa cita el lenguaje "neutro" de los juristas?

A diferencia de los procesos penales típicos, donde se rastrea la evidencia para “descubrir" tras el desfile de prueba si existió o no culpa de parte de un imputado, apenas comenzamos la lectura de Puño y letra hallamos al culpable, el emisor de una epístola afectuosa dirigida a Carlos Prats González. Su autor es Augusto Pinochet. El que su letra y promesa de amistad comparezca a esa sala del tribunal y lo haga tan desordenadamente dentro de la cronología de los acontecimientos que se intentarán exponer o tejer posteriormente, constituye un juicio determinado de antemano por la autora. Ésta se erige en juez y dicta un veredicto antes de comenzar el juicio, convirtiendo la carta-documento en prolepsis del crimen; no el motivo sino la falla ética equivalente a la traición de la amistad. Pone así de manifiesto los dos tiempos de la narración: el antes de la carta que indujo al engaño o la traición al orden constitucional, y la retórica del juicio en el juzgado público donde la norma jurídica relativa al descubrimiento paulatino de la prueba dictamina reorganizar los materiales de acuerdo a las expectativas retóricas que orientan las preguntas que inquieren la culpabilidad. Más allá del preámbulo, la autora adjudica responsabilidad a una persona que no concurre al juicio y ni siquiera es acusado en éste: quien concurre al juzgado en el relato de Eltit no es Arancibia Clavel, sino Augusto Pinochet, aunque in absentia. Su seña es la epístola, edulcorante comunicación no feliz que caracteriza su enunciado y que funciona como detonante de los hechos posteriores. Comparece Pinochet a través de su carta enviada a Prats, que ubicada en el pórtico de esta novela adquiere el paradójico valor del falso testimonio equivalente a la traición. Dicho esto, de ahí en adelante Eltit permite que la acumulación de la prueba marche

\footnotetext{
Revista Iberoamericana, Vol. LXXVIII, Núm. 241, Octubre-Diciembre 2012, 1013-1026 ISSN 0034-9631 (Impreso) ISSN 2154-4794 (Electrónico)
} 
por sí sola hacia el futuro previsible de la culpa, aunque imputable a otro durante el juicio público. Pero ya ha advertido al lector respecto al verdadero imputado del juicio y respecto a los cargos: alta traición de Pinochet. La salvedad de esta primera página que allí coloca Eltit ya nos advierte sus énfasis. Al desordenar la cronología narrativa, desata el comentario: la impaciencia del pueblo chileno respecto a un proceso demorado por años y respecto a la identidad del inculpado. Destaco de la carta las falsas pistas de amistad connotadas en una afectividad excesiva. Eltit hace comparecer a Pinochet mediante la carta para denotar la omisión deliberada de su interpelación jurídica como parte de este juicio. La testigo presencial induce a sus lectores a pensar que no se trata de Arancibia, sino de Pinochet. Tampoco se trata necesariamente de Prats, sino de todo el pueblo chileno. Es decir, las partes involucradas y antagónicas (el asesino y la víctima) no han sido citadas cabalmente. Esta posición de no trascender la individualización del asesinato político por razón de su judicialización permite plantearse si acaso habría que celebrar otro juicio porque éste no basta. Y aún más, si es posible el juicio, dado que en un proceso penal quien formula la acusación simbólicamente es el pueblo o el Estado soberano y, bajo dictadura, inculpar al dictador constituye la máxima imposibilidad. Ello constituiría el primer sesgo de autor. En otras palabras, ¿es la opción jurídica una opción política en esas circunstancias?

El interrogatorio del testigo, la transcripción de las respuestas de Zambelli, sólo permiten exhibir la fragilidad, fallas e inconsistencias de la memoria de un sujeto que ha sido sometido a varios interrogatorios y la necesidad de la prueba de que éste rememore las actividades sospechosas de su amigo Arancibia (viajes frecuentes entre Chile y la Argentina, identidades diversas, posibles fallas de carácter). Pero, sobre todo, coloca la mira sobre Zambelli y su condición de artista de farándula y homosexual en lugar de Arancibia. El tribunal se presta a explotar la posible lectura conservadora de un hombre apolítico que confiesa una y otra vez que ya no puede recordar bien. Esa "impertinencia” de su relevancia como testigo le sirve más a la defensa de Arancibia que al fiscal, dado que desvía la atención hacia la no credibilidad de su testimonio por ser quien es, un artista apolítico dentro de una trama que desconoce. Zambelli no deja de ser una víctima del proceso judicial, más que una pieza con algún valor testimonial. Se trata de extraer mediante el interrogatorio un testimonio que termina confirmando lo que desconoce, y para nosotros lectores sirve para medir la habilidad mentirosa de Arancibia, y no la falta de credibilidad del testigo. Lo que se desprende de sus respuestas no es la verdad, sino el proceso de su engaño. Su relato de los hechos, así como su credibilidad, son disputados; y sumido en ese engaño respecto a la identidad de Arancibia es prácticamente reducible al niño que no puede testificar porque aún no tiene capacidad de hacerlo. Si, como dice Ricoeur, el testimonio no es el percibir mismo, sino el informe de lo percibido, es decir, la narración del evento que permite transferir lo visto al plano de lo dicho (123), Zambelli es incapaz de dar testimonio porque no vio y aún más, si lo

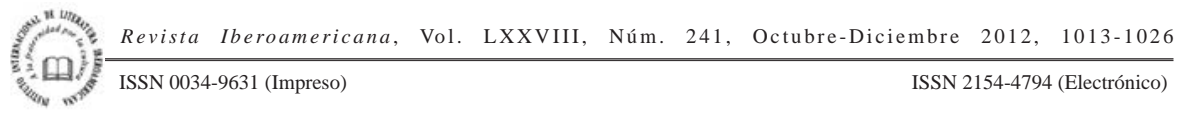


vio no sabe lo que vio: sólo puede realizar actos relativos a su memoria, rememorar su propia vida. De ahí que el interrogatorio constante y su fragmentación indique lo que es: la imposibilidad de narrar una historia. He aquí entonces al testigo que no lo es, he aquí un falso testigo, no por lo que dice, sino por lo que deja de decir porque no entiende. Su posición le permite a los lectores asistir a una puesta en escena donde el personaje lo dice todo en el acto de decir nada, de preguntarse por qué Zambelli aquí. Zambelli sirve para confirmar la duplicidad de Arancibia, quien incluso a su pareja íntima no le revela quién es. Por tanto, ¿¿quiénes son los testigos? Esta pregunta atañe principalmente a Eltit como espectadora-autora y a nosotros cual lectores. Es Eltit quien prepara la escena y selecciona este documento ocupando allí su oído para escuchar el testimonio que no es. Es Eltit quien transfiere lo visto y lo escuchado, el juicio oral, al plano de la narración. El asumirse como testigo es la forma que halla para asumirse como "una más” en la comunidad del agravio. Y, precisamente, porque lo hace logra comprender la magnitud del crimen, concentrada en la palabra "alevosía”.

"Enrique, Juan, Juan Felipe, Luis Felipe y Miguel” son los alias conocidos de un personaje absorto en su "propia ficción”, proteico y narcisista, el inculpado, de quien la autora destaca su falsedad, su necesidad de reconocimiento y su falta grave de disciplina. Su nombre verdadero es Enrique Lautaro Arancibia Clavel. Su necesidad de recurrir a heterónimos y a ocultar su identidad produce un paralelismo entre sala judicial y escenario teatral, que la autora evoca en la imaginación cinéfila: “[...] pareciera que estuviese actuando la ficción cinematográfica de un soldado capturado que fuese sometido, en un territorio que le es adverso, a un consejo de guerra” (Eltit 21). La alusión es medular porque establece una analogía entre el proceso contra este sombrío adlátere del ejército pinochetista y el Juicio de Nuremberg, donde se acusa a los dirigentes supremos del Tercer Reich. Aquí vale la pena un paréntesis concerniente a la tesis de Shoshana Felman relacionada al vínculo existente entre el trauma colectivo y el inconsciente jurídico. Al discutir dos juicios cruciales del siglo xx, el de O. J. Simpson y el de Adolf Eichmann, propone Felman que todo gran juicio contiene la cita de un juicio anterior, a saber, lo que llamamos en derecho, el valor del precedente. En el caso de esta novela, es el Juicio de Nuremberg y la atmósfera ritual que generan los medios informativos que cubren el caso, el precedente evocado, el cual está investido con el halo de la parodia, pues aquí el personaje asume una grandilocuencia excesiva. La representación ubicable en la Argentina no excluye el mismo sentimiento de indignación -"muy chileno", aclara la autora- y la subsistencia del "tiempo político que nunca ha cesado". La forma en que describe las sensaciones corporales provocan extrañeza, vacío, caos, tensión, una incesante sensación de violencia, que fue la atmósfera prevaleciente durante el régimen de terror pinochetista. La autora desempeña el papel de comparecer como "testigo ocular" del proceso, y no desaprovecha la ocasión para juzgar moralmente al personaje antes de que comience la “acción”. Dicha acción (que en un juicio consiste en la argumentación)

\footnotetext{
Revista Iberoamericana, Vol. LXXVIII, Núm. 241, Octubre-Diciembre 2012, 1013-1026 ISSN 0034-9631 (Impreso) 
depende exclusivamente de los documentos: consistirá en la transcripción de los pliegos testimoniales, uno referente a la incapcidad de Zambelli, y otros dos provenientes de los abogados que logran vincular a Arancibia con la DINA (Dirección de Inteligencia Nacional de Chile) e identificar dicha agencia como la policía secreta de Pinochet. Esta cadena inculpatoria relacionada con la causalidad constituye la prueba definitiva de atribución del asesinato imputable a quien es juzgado in absentia por la autora, al autor de la carta que inicia el desfile de prueba. Es decir, cuando se inicia formalmente el juicio contra Arancibia, Eltit insinúa un juicio paralelo, el de Pinochet, cuyos asesinados son el pueblo, la democracia, el sistema constitucional, toda una atmósfera de tensión y violaciones de los derechos humanos que aún no ha sido reparadas. Bajo este esquema, el trauma resulta insuperado y conforma la segunda piel del pueblo chileno; se trata de una herida abierta que se niega a cerrar. Felman subraya la imposibilidad de la cauterización dado que el trauma es inconmensurable vis à vis lo que el derecho pretende resarcir; de ahí su abocación infinita a repetirse. ${ }^{2}$

De otro lado, los abogados de la familia Prats se ocupan de probar la cadena de mando y responsabilidad penal atribuible a Pinochet, precisamente porque la DINA es una agencia estatal que incurre en actos ilícitos de clandestinaje. Para probarlo, los abogados utilizan los testimonios recogidos en el Informe de la Comisión Nacional de Verdad y Reconciliación ${ }^{3}$ y el Informe Rettig, avalado por una Ley del Congreso chileno. ${ }^{4}$ El propósito del argumento es probar que la acción de la DINA en la Argentina "fue la actuación de una asociación ilícita calificada” (Eltit 149), que Arancibia pertenecía a dicha asociación y que los memos encontrados al allanarse su domicilio estaban escritos de "puño y letra” del acusado. Además, se prueba que el acto ilícito comenzado en 1974 es regido por la ley vigente al terminar la conducta equivalente a la asociación ilícita, y que la acción pone en peligro la Constitución Nacional. Respecto al cargo del doble homicidio agravado tan sólo se alude al hecho material de la explosión ocasionada por un artefacto explosivo que se colocó debajo del automóvil. Con ese dato termina su alegato. Al exponer el abogado Luis Moreno Ocampo, éste destaca la identificación de Arancibia (único hombre de la DINA en Buenos Aires cuando ocurre el atentado) como un engranaje dentro de la DINA, por lo que es el Estado el responsable último

2 "I argue that it is because of what the law cannot and does not see that a judicial case becomes a legal trauma in its own right and is therefore bound to repeat itself through a traumatic legal repetition" (Felman 57).

3 En específico, el de Federico Willoughby que era vocero de la Junta Militar de Chile. La agencia se oficializó bajo el Decreto 521 de junio de 1974, pero comenzó a actuar extraoficialmente a fines de 1973. El alegato señala que la prueba documental indica que la DINA “dependía directamente de quien ejercía la Presidencia de la Junta primero y la Presidencia de la República después” (Eltit 139).

4 Según el testigo Corrrea Sutil, “[...] ninguna de las observaciones o ninguna de las calificaciones efectuadas en el informe fueron seriamente cuestionadas, digamos...con pruebas, ¿no? Por supuesto, hubo intentos de cuestionarlo, pero no con pruebas" (Eltit 141).

Revista Iberoamericana, Vol. LXXVIII, Núm. 241, Octubre-Diciembre 2012, 1013-1026
ISSN 0034-9631 (Impreso) 
de varios asesinatos. En particular, el de Prats tuvo que haber pasado por la anuencia de Pinochet, por ser Prats el ex-comandante en jefe del ejército chileno. El hecho de no haberle rendido honores ni homenaje a su muerte confirma la trama. Dice el letrado: "Por eso no le rinden honores. Porque Pinochet había ordenado su muerte, por eso no estaba dispuesto a rendirle honores” (159). Señala el letrado que la única forma que podría excusar su responsabilidad en el crimen sería habiéndose negado a la participación y probarlo ante la corte. Es este abogado el único que rebasa el término técnico usado a lo largo del juicio (el doble homicidio) llamando el acto por su nombre: un crimen.

La solicitud de pena máxima (prisión perpetua), queda en manos del abogado Luis Moreno Ocampo. El abogado recalca que representa a las familias, pero que el veredicto trasciende lo individual y que "Es un caso muy importante para cualquier ciudadano, no solamente argentino o de Chile sino del mundo, preocupado por la vigencia de la ley” (Eltit 177). Destaca una palabra al aludir a la bomba: "un acto de alevosía” (179). 'Alevosía' es la misma palabra que utiliza Eltit en la presentación, lo cual remite al hecho de que aun identificado el culpable del crimen, adjudicada la culpa, y dictado el veredicto de pena máxima, "la alevosía no cesa”. Son las palabras que siguen al veredicto fuera de la sala judicial, la sensación sufrida pese al dictamen. La autora sale a la calle y siente que la alevosía sigue allí. La continuidad de la afrenta del mal es lo que no restaña el procedimiento jurídico. La alevosía, la planificación, la premeditación, "la cautela con que el delincuente asegura la comisión de un delito contra personas, evitando el riesgo procedente de la defensa del ofendido" es lo que permanece impune. La traición es el delito y revisitada la carta con que comienza el desfile de prueba, el delito más grave. Con esto Eltit revoca las palabras del abogado de "que condenarlo será justicia". Es decir, la justicia no satura la herida aún abierta.

Probablemente, más allá de los paralelismos trillados entre juzgado y teatro como espacios de representación, lo esencial aquí sea la afirmación que sostiene la producción del texto, uno que privilegia el papel de la autora como lectora del simulacro judicial y postulante del reclamo de un espacio social todavía en proceso que expone las contradicciones de la judicialización de lo político. Dice Eltit: "Este caso es, en cierto modo, una metáfora. Tal vez cruel, con seguridad demasiado nítida, pero en medio de esta escenografía judicial da vueltas y vueltas la génesis de un crimen fraguado en el interior de sus propias cúpulas rompiendo ferozmente las estructuras” (25-26). La presentación de las mujeres de cada familia agudiza la estructura adversativa del proceso, pero sobre todo subraya la imposibilidad de la reconciliación en un espacio político donde todos escabullen la culpa, excepto las mujeres que comparecen o "dan la cara” (27) en un proceso exclusivamente individual donde gran parte de la disputa es borrada por los aderezos del rito institucional jurídico ("No habrá acuerdo entre estas mujeres, pienso") (26). Adscribirle el papel conservador de las mujeres lorquianas a las Arancibia y, en cambio, ubicar a las hermanas Prats en el esquema del reclamo

\footnotetext{
Revista Iberoamericana, Vol. LXXVIII, Núm. 241, Octubre-Diciembre 2012, 1013-1026 ISSN 0034-9631 (Impreso) 
contra el poder tiránico ajusta sutilmente la mira de la oposición entre ambos bandos. Lo que buscan las últimas es una "sepultura simbólica definitiva para sus padres" (26), mientras que los agentes verdaderos de la acción se ausentan. En suma, el reclamo no trasciende lo individual, y el inculpado no deja de ser un chivo expiatorio. Además, se trata de una "escena jurídica tardía" (28) acaso ya desprovista de sentido, pregunta que no se contesta nunca en la obra, dado que la tenencia de sentido de este proceso quizás se cumple con su transcripción indignada en esta novela-documento llamada Puño y letra. Queda la pregunta de qué hacer o cómo localizar a una persona que deriva placer del síndrome de "múltiple identidad", porque reconduce su necesidad de hacerse válido en éste su complejo de sentirse nadie en la organización militar, un peón en "una trama que lo excedía”. Aquí aparece definitivamente la razón de su texto, que atañe a la necesidad de nombrar la ausencia, que Eltit denomina "asimetría jurídica”. Pero mejor lo dice después: "No están los otros. Sus jefes. No están, entre otros personajes, Augusto Pinochet o el entonces Mayor Raúl Iturriaga Neumann o el antaño Coronel Luis Barría Barría. Faltan los militares 'de verdad'. Son cuerpos ausentes y, no obstante, cruciales para conformar una escena definitiva” (30). Ella reconoce que se ha convertido en testigo del juicio, pero no se distingue como especial, sino "una entre otras, entre otros” (34). Es decir, la estructura revela la intención de esta novela-documento pues en la Presentación se incluyen la carta de Pinochet, el cargo y el personaje. A través de todos estos pasajes, y encabezándolos con su testimonio, primero comparece Eltit en primera persona, quien ejerce derechos como lectora, testigo y autora simultáneamente. Si en un proceso penal el Estado ocupa la posición de los directamente afectados por la comisión del delito, mediando entre las partes afectadas para evitar la venganza y señalar que el delito es un agravio al estado constituido, Eltit se erige en una especie de juez supremo que reclama trascender los límites inherentes a la institución judicial, y como una sufriente más del terror deviene en esta instancia testigo ocular y lectora, por ser chilena y parte del pueblo agraviado. La obra, entonces, presenta verbatim un proceso judicial, pero sobre todo re-presenta su insuficiencia. La transcripción de los legajos es un gesto (paradójicamente) inútil con sentido, y ese sentido lo debemos extraer nosotros como lectores, derivando del proceso de lectura algo más.

II.

Pero yo no "cuento una historia", lo que hago es poner en escena un fragmento documental de orden político que ya formaba parte de la memoria chilena.

Diamela Eltit

Puño y letra es una especie de testimonio, si lo pensamos en el sentido en que ha sido definido el término por la academia norteamericana. Visto desde esa perspectiva,

Revista Iberoamericana, Vol. LXXVIII, Núm. 241, Octubre-Diciembre 2012, 1013-1026
ISSN 0034-9631 (Impreso) 
aquí se romperían sus coordenadas porque se destruye la convención de que un miembro de la intelligentsia dialogue con un subalterno a fin de que éste pueda decir (Franco). ${ }^{5}$ Más bien, aquí se invierten estas claves analíticas y Eltit, una mujer escritora, asume el puesto de testigo y reclama sufrir como chilena. La narración en primera persona deviene un sujeto plural, que desempeña el papel de testigo ocular de un evento, por lo que estar presente allí constituye un momento importante de su vida (Beverley). No hay reclamo de verdad respecto a lo narrado pues los documentos hablan por sí solos, pero mediante el encuadre previo y final, la autora cuestiona la institución judicial, prestigiada por la sacralidad simbólica de la que está investida, de su espacio de influencia, socavándola desde un principio y arrogándose simultáneamente el papel de testigo y juez de ésta. Puede decirse que secuestra para su texto los documentos judiciales, colocándolos en un contexto diverso donde esgrime la palabra clave de la subjetividad criminal, la "alevosía", y pone en entredicho la efectividad de la pena. En ese sentido, se ha apropiado de un poder interpretativo (el de la autoridad judicial) para torcer el rumbo de lo exclusivamente jurídico. Eltit toma como protagonista a la institución judicial misma, así como la tecnificación de su lenguaje, y problematiza lo que esta institución puede hacer, que es poco, como puntualiza indirectamente a lo largo del texto. Si bien la autora irrumpe ensayísticamente enmarcando valorativamente toda la acción, gesto característico del género testimonial (Vera León), la conclusión o interpretación del gesto autorial reposa en nosotros, a quienes coloca en la posición de jueces éticos del acto. No es de doble homicidio por el que se acusa a Arancibia, sino de algo que lo rebasa y no se dice, la destrucción de una comunidad estatuida y la violación de sus cuerpos, un acto que trasciende la violación de los derechos humanos. Si como dice Badiou, la justicia debe definirse afirmativamente y consiste en el reconocimiento en la víctima de su espíritu, así como de su cuerpo, diría que esta obra es un ajusticiamiento, donde la espectadora comparece como "una más" del pueblo chileno, hace el reclamo respecto a la insuficiencia de la escena jurídica y se consolida como actuante, burlando el rol pasivo de la víctima. En esto consiste, como dice Badiou, la justicia: "[...] pasar de la condición de víctima a la condición de alguien que está de pie” (25).

La evocación del daño causado por el régimen en el "cierre transversal” de la última parte inserta lo autobiográfico en el esquema de la judicialización penal, pero es también el momento en que la víctima de esta metáfora se resiste a serlo. En este caso, la consolidación permanente del trauma se evidencia en la frase repetida doblemente: "la alevosía no cesa". El juicio, pues, es una forma diferente de escribir la autobiografía de todos, de una generación traumada que asiste como espectadora a un juicio que no

5 Reconocemos además toda una vertiente testimonial que no coincide con el esquema señalado, desde los relatos del Che Guevara, Payeras, Cabezas, hasta los textos híbridos de Eltit, Arce, etc.

Revista Iberoamericana, Vol. LXXVIII, Núm. 241, Octubre-Diciembre 2012, $1013-1026$
ISSN 2154-4794 (Electrónico) 
remedia la violencia, pues la herida no cierra ${ }^{6}$ El empotramiento literario del evento judicial desarticula los poderes que puedan ejercer quienes determinan el veredicto, y lo potencian de otra forma al convertir en verdadero documento público unos legajos jurídicos destinados originalmente al consumo exclusivo de los juristas. Esta puesta en circulación como novela potencia su lectura al multiplicar a sus lectores, pero sobre todo incentiva un gesto de indignación al exponer las circunstancias cuasi neutrales o grises en que un ajusticiamiento, que debió ser político, se judicializa. ¿Cuál de los dos esquemas da mejor fe de la justicia, el jurídico o el estético? Recordemos que el derecho es un orden tan jerárquico como la milicia, uno de los poderes que mantiene el status quo. Como señala Bourdieu en su crítica al análisis estrictamente lingüístico de Austin, quien inviste de poder al poder es la misma gente en la operación de magia social que constituyen los actos de autoridad. El poder de las palabras depende del poder de un portavoz así reconocido por las instituciones para que actualice el rito de institución o la lengua legítima. El reconocimiento del discurso de autoridad, independientemente de que sea comprendido, sólo ocurre bajo las condiciones que concede el uso legítimo: el ser pronunciado en condiciones legítimas y por la persona legitimada, el poseedor del cetro (sacerdote, profesor, poeta). El lenguaje de autoridad sólo funciona con la colaboración de aquéllos a quienes gobierna, “[...] mediante la asistencia de los mecanismos sociales capaces de producir esta complicidad, fundada en el desconocimiento, y que es el origen de toda autoridad” (73). Por eso, la torsión realizada por Eltit consiste en apropiarse del lenguaje que le es vedado, el lenguaje y el escenario exclusivo de los juristas, para autorizarse en el espacio híbridamente jurídico que construye, para decir desde la ficción lo que el derecho es incapaz de decir para lograr la justicia. Además, el esquema de la judicialización confirma la incapacidad del tribunal para descubrir el crimen o la violencia mayor, es decir, la destrucción de toda una generación. Del asesinato general no da cuenta el juicio, porque aquí la víctima es una y el juzgado es el equivocado. Más bien, la atribución o apoderamiento realizado por Eltit se opera mediante la capacidad de reorganizar los documentos, intervenir de antemano en la identificación del culpable al insertar la carta al principio y preparar el escenario para que percibamos el proceso de otra forma. La larga cita jurídica estimula la inquietud de un lector lego que desconoce hacia dónde marcha el argumento, hasta el punto que el último abogado que expone se libera del argot jurídico para llamar las cosas por su nombre y mencionar al culpable. Su clamor por lo justo, que sería dictar un veredicto de prisión perpetua, es insuficiente. No es ello conmensurable con la idea de justicia que se desprende de los comentarios de la autora. Para ésta, la clave reside

6 "I argue that it is because of what the law cannot and does not see that a judicial case becomes a legal trauma in its own right and is therefore bound to repeat itself through a traumatic legal repetition" (Felman 57).

Revista Iberoamericana, Vol. LXXVIII, Núm. 241, Octubre-Diciembre 2012, 1013-1026
ISSN 0034-9631 (Impreso) 
en la palabra "alevosía” o la premeditación que precede al asesinato, y el hecho de que la víctima no es una, sino una generación.

El acto de Eltit de asumirse como "una más” genera un sujeto plural que al concluir la obra evoca el otro crimen: los efectos del golpe y específicamente el año 74 en que se asesinó a Prats y a su esposa, se proclamó presidente Pinochet, se estableció la DINA, y la mayoría asumió la impasibilidad como la única respuesta posible bajo ese estado de excepción. El que se inicie el último capítulo aludiendo a otros dos asesinados que nadie conoce, abaleados en una acequia, es reiterar la afirmación primera de que todas las demás víctimas han sido invisibilizadas tras el parapeto del juicio de Prats. Por momentos, al negarse a describir el estado en que quedó el cuerpo de Sofía Cuthbert después del bombazo, la autora parecería adscribirse a la tesis de Feldman de que el horror es irrepresentable. Al aludir al pudor que no la deja describir, ese cuerpo quedó fuera de la escena, pero no tanto, porque en el lugar de ese cuerpo destrozado, describe el de su generación, no menos terrible en su dureza: “[...] en 1974 nuestro opaco y penoso adentro ya había terminado por consolidarse” (Eltit 190). Sin embargo, más que mostrar, el rumbo de esta novela es exhibir un gesto insuficiente y responder activamente a ello. El gesto es llevado a cabo por el deseo de reconciliación y la propuesta de llevar los criminales a los tribunales.

Mediante esta "novela” Eltit emplaza al tribunal, quizás porque sus palabras son insuficientes pues no son equiparables al mal realizado. De boca de los juristas sale un discurso incomprensible, tan incomprensible como el del Padre mío, pero en este caso el decirlo imposibilita las características del lenguaje formal e impenetrable del técnico designado exclusivamente para el entendimiento entre iguales. El texto que se resiste a ser leído (los documentos empotrados) está desprovisto de pathos y de verdad. He aquí un discurso incorporado que constituye el 80\% del libro, puesto ahí para probar su ineficiencia y para solicitar una reacción. La primera re-actora es la autora que lo socava desde adentro añadiéndole la carga emotiva desprovista en aquél. El llamarlo una "metáfora" le permite colocarse a sí misma como testigo y sufriente de este evento, pero a una segunda potencia. Su habla desentraña el sentido; le suple un significado ulterior pues su exposición no depende de la necesidad de probar una culpa que todos conocen. He aquí un texto que no tiene nada que revelar, y por eso es imposible conmoverse con lo que el desfile de prueba pueda descubrir. Lo que dicen los abogados pertenece al conocimiento empírico, no hay expectativa en la lectura que pueda hacerse aquí porque no hay acción desconocida ni psicologías que sorprendan, tampoco motivación que no se sepa. Ya todo se sabe. Lo que falta es la reparación. Ante la impenetrabilidad de la voz institucional, Eltit la socava desde sus márgenes y asume su posición pasando por encima de los cadáveres para hablar por los sobrevivientes. Es este el gesto fundamental, y ya por ese medio se representa la violencia, que asume dos formas, exhibir el forjamiento paulatino de la alevosía, así como el camino tortuoso del ajusticiamiento mediante este

Revista Iberoamericana, Vol. LXXVIII, Núm. 241, Octubre-Diciembre 2012, 1013-1026 ISSN 0034-9631 (Impreso) 
juicio, que no es más que una forma gris, neutral, demorada, de resarcir una afrenta histórica. No deja de ser otra violencia el dirimir el suceso en un tribunal, y por eso, la respuesta de Eltit al usar las propias palabras del juicio para ejercitar su crítica, la insuficiencia del lenguaje jurídico judicial. Al transcribir activamente sus palabras, no sin antes comentar todo el escenario y escoger precisamente esos dos fragmentos donde la técnica y el eufemismo ocultan los cadáveres, ejerce un control total de la lectura, y transcribiendo les es fiel: los representa tal cual. La fina cuerda que atraviesa la autora consiste en que a la vez que el juicio es necesario, no es suficiente. Los abogados están inmersos en las trampas de un lenguaje que no les permite ser explícitos y son parte de una institución de la que no pueden renegar. La novela logra romper el cerco, citando un texto insuficiente que no deja de ser representativo de un momento que debe superarse por otro ulterior, dada la exigencia política que no le es dable satisfacer desde la judicialización. Vale la pena reflexionar qué nos plantea este texto desde el punto de vista de la justicia transicional y de la retribución cuando un juicio no remedia el acto mismo del ultraje (Mañalich). Aguardo el momento de ampliar lo que planteo aquí, de las implicaciones que tiene un texto como éste en su diálogo más profundo con otros aspectos del derecho durante y después del terror estatal.

Es preciso pensar en los detalles del juicio: la naturaleza de los cargos (doble homicidio), el lugar donde se juzga (lejos de Chile, Argentina), la judicialización de lo político y, sobre todo, la lectura del juicio ejercitada por Eltit, que comparece como lectora y jueza o evaluadora del doble asesinato. Usando un lenguaje antiliterario, como ella misma expresa, su acción textual ya es política pues extiende el juicio a otro ruedo. Sale del cerco de la individuación del cargo penal para insertarlo en la incomensurabilidad de lo que el fenómeno literario permite decir sin decir a través de la metáfora. Aquí los límites de la representación se ven cuestionados, así como el concepto de testimonio, la polémica respecto a la imposible reparación de lo sagrado que hay en cada humano dentro del estrecho ámbito de los derechos humanos y la vulgarización del Derecho conjuntamente con el vaciamiento del reclamo del "nunca más” en la esfera política dejándolo en el ámbito de la reparación personal a través del derecho penal. Al comentar la autoridad conferida a quien posee la lengua legítima, señala Bourdieu que "el misterio de la magia performativa se resuelve en el misterio del ministerio [...], es decir, en la alquimia de la representación a través de la cual el representante constituye el grupo que le constituye a él: el portavoz dotado del poder de hablar y actuar en nombre del grupo, y en primer lugar sobre el grupo que existe única y exclusivamente por esta delegación”. Aquí Eltit asume el derecho de hablar por una generación, se identifica con el cuerpo que encarna y "se entrega en cuerpo y alma”, proveyendo así un cuerpo biológico a un cuerpo constituido. Interesante que el veredicto del juez que nunca emite una sola palabra, se halla inmerso en las palabras de Eltit, que ya desde antes ha devenido juez, además de declarar la precariedad y

Revista Iberoamericana, Vol. LXXVIII, Núm. 241, Octubre-Diciembre 2012, 1013-1026
ISSN 0034-9631 (Impreso) 
fragilidad de un proceso signado por la teatralidad, y su insuficiencia, al insistir que la "alevosía" no termina. Contrario a lo ocurrido en otros juicios donde se remedia tan sólo parcialmente el trauma de una colectividad (Simpson, Eichmann), aquí lo judicial no remedia el dolor humano ni el político, tampoco la perturbación de la testigo ocular del juicio. De esto Eltit está consciente, y por eso el texto la libera de esa esfera en una suerte de doble exposición al reiterar con un valor distinto algunos momentos del juicio y transmitirlos a los lectores. El encuadre le permite sobreseer la causa, lanzarla hacia el futuro, descoyuntarla del presente histórico de un juicio como tantos en la década del dos mil. Al entregar su sentencia se autoriza y nos emplaza.

\section{BiBLIOGRAFÍA}

Atria, Fernando. "La hora del derecho”. Copia personal.

Badiou, Alain. "La idea de justicia”. Justicia, filosofía y literatura. Silvana Carozzi, ed. Rosario: Homo Sapiens, 2007. 25.

Beverley, John. "Introducción”. La voz del otro: testimonio, subalternidad y verdad narrativa. John Beverley y Hugo Achúgar, eds. Ciudad de Guatemala: Universidad Rafael Landívar, 2002. 17-29.

Bourdieu, Pierre. "El lenguaje autorizado: las condiciones sociales de la eficacia del discurso ritual”. ¿Qué significa hablar? Madrid: Akal/Universitaria, 1985. 67-77.

Eltit, Diamela. Puño y letra. Juicio Oral. Barcelona: Seix Barral, 2005.

Felman, Shoshana. The Juridical Unconscious. Trials and Traumas in the Twentieth Century. Cambridge: Harvard UP, 2002.

Franco, Jean. "Si me permiten hablar: la lucha por el poder interpretativo". La voz del otro: testimonio, subalternidad y verdad narrativa. John Beverley y Hugo Achúgar, eds. Ciudad de Guatemala: Universidad Rafael Landívar, 2002. 121-128.

Mañalich R. Juan Pablo. Terror, pena y amnistía. El Derecho penal ante el terrorismo de Estado. Santiago de Chile: Flandes Indiano, 2010.

Matus, Álvaro. "Escritora de avanzada”. Revista de Libros de El Mercurio. 4 nov. 2005. <www.letras.s5.com/de190106.htm>. 8 oct. 2012.

Rancière, Jacques. “Aesthetics as Politics”. Aesthetics and its Discontents. 2004. Steven Corcoran, trad. Cambridge: Polity Press, 2009.

Ricoeur, Paul. "The Hermeneutics of Testimony”. Essays on Biblical Interpretation. Lewis S. Mudge, ed. Philadelphia: Fortress P, 1980. 119-154.

Sotomayor, Áurea María. “Tres caricias: una lectura de Luce Irigaray en la narrativa de Diamela Eltit”. Femina Faber. Letras, música, ley. San Juan: Ediciones Callejón, 2004.

Vera León, Antonio. "Hacer hablar: la transcripción testimonial”. La voz del otro: testimonio, subalternidad y verdad narrativa. John Beverley y Hugo Achúgar, eds. Ciudad de Guatemala: Universidad Rafael Landívar, 2002. 195-213.

\footnotetext{
Revista Iberoamericana, Vol. LXXVIII, Núm. 241, Octubre-Diciembre 2012, 1013-1026 
Watanabe, José. Antígona (Versión libre de la tragedia de Sófocles). San Juan: Fragmento Imán, 2010.

Revista Iberoamericana, Vol. LXXVIII, Núm. 241, Octubre-Diciembre 2012, 1013-1026
ISSN 0034-9631 (Impreso) 